\title{
Hydrostatic Parameters and Domain Effects in Novel 2-2 Composites Based on PZN-0.12PT Single Crystals
}

\author{
Vitaly Yu. Topolov, ${ }^{1}$ Sergei V. Glushanin, ${ }^{2}$ and Alexander A. Panich ${ }^{2}$ \\ ${ }^{1}$ Department of Physics, Southern Federal University, 5 Zorge Street, Rostov-on-Don 344090, Russia \\ ${ }^{2}$ Scientific Design \& Technology Institute "Piezopribor," Southern Federal University, 10 Milchakov Street, \\ Rostov-on-Don 344090, Russia
}

Correspondence should be addressed to Vitaly Yu. Topolov, vutopolov@sfedu.ru

Received 18 October 2010; Accepted 26 January 2011

Academic Editor: Zhifei Shi

Copyright (C) 2011 Vitaly Yu. Topolov et al. This is an open access article distributed under the Creative Commons Attribution License, which permits unrestricted use, distribution, and reproduction in any medium, provided the original work is properly cited.

A novel $0.88 \mathrm{~Pb}\left(\mathrm{Zn}_{1 / 3} \mathrm{Nb}_{2 / 3}\right) \mathrm{O}_{3}-0.12 \mathrm{PbTiO}_{3}$ crystal/polymer composite with 2-2 connectivity is studied at variable orientations of spontaneous polarisation vector of the crystal component. Orientation and volume-fraction dependences of the hydrostatic piezoelectric coefficients $d_{h}^{*}, e_{h}^{*}$, and $g_{h}^{*}$ and hydrostatic electromechanical coupling factor $k_{h}^{*}$ are related to the important role of the piezoelectric and elastic anisotropy of single-domain layers of the 2-2 composite. The record value of $\left|e_{h}^{*}\right| \approx 77 \mathrm{C} / \mathrm{m}^{2}$ near the absolute-minimum point and the correlation between the hydrostatic $\left(e_{h}^{*}\right)$ and piezoelectric $\left(e_{3 j}^{*}\right)$ coefficients and between the hydrostatic $\left(g_{h}^{*}\right)$ and piezoelectric $\left(g_{3 j}^{*}\right)$ coefficients are first established. This discovery is of value for hydrostatic and piezotechnical applications. The hydrostatic performance of the composite based on the single-domain $0.88 \mathrm{~Pb}\left(\mathrm{Zn}_{1 / 3} \mathrm{Nb}_{2 / 3}\right) \mathrm{O}_{3}-0.12 \mathrm{PbTiO}_{3} \mathrm{crystal}$ is compared to the performance of the 2-2 composites based on either the same polydomain crystal or the related single-domain crystal.

\section{Introduction}

The polarisation orientation effect in advanced piezo-active composites based on relaxor-ferroelectric single crystals (SCs) of $(1-x) \mathrm{Pb}\left(\mathrm{Zn}_{1 / 3} \mathrm{Nb}_{2 / 3}\right) \mathrm{O}_{3}-x \mathrm{PbTiO}_{3} \quad(\mathrm{PZN}-x \mathrm{PT})$ [1-3] and $(1-y) \mathrm{Pb}\left(\mathrm{Mg}_{1 / 3} \mathrm{Nb}_{2 / 3}\right) \mathrm{O}_{3}-y \mathrm{PbTiO}_{3}(\mathrm{PMN}-y \mathrm{PT})$ $[3,4]$ opens up new possibilities of the variation of effective parameters of the composites that are of value for modern hydroacoustic and piezotechnical applications. The anisotropic SC component with large piezoelectric coefficients (e.g., $d_{3 j}^{(1)} \sim 10^{3} \mathrm{pC} / \mathrm{N}$, hereafter we use superscript "(1)" to denote electromechanical constants of the SC component) $[5,6]$ plays an important role in forming the piezoelectric effect of the composite and its hydrostatic piezoelectric response, as shown in recent papers on the 2-2 [1, 3, 4] and 1-3 [2] SC/polymer composites. The 2-2 parallel-connected composite based on the single-domain PMN-0.33PT SC [4] is an example of a piezoelectric material whereby large hydrostatic piezoelectric coefficients are achieved at specific orientations of the crystallographic axes and SC volume fraction. As is known, the chemical composition of PMN-0.33PT is located near the morphotropic phase boundary, and the PMN-0.33PT $\mathrm{SC}$ in the single-domain state is described by $3 \mathrm{~m}$ symmetry at room temperature [7]. Along with electromechanical constants of PMN-0.33PT, there are complete sets of roomtemperature electromechanical constants (Table 1) measured on the single-domain PMN-0.42PT [5] and PZN-0.12PT [8] SCs with $4 \mathrm{~mm}$ symmetry. We see the difference between the piezoelectric coefficients $d_{i j}^{(1)}$ of PMN-0.42PT and PZN$0.12 \mathrm{PT}$ SCs, for which the order of magnitude of $d_{i j}^{(1)}$ remains $10^{2} \mathrm{pC} / \mathrm{N}$ (Table 1 ). We note that the single-domain PZN-0.12PT SC exhibits a distinctive elastic anisotropy in comparison to that of the single-domain PMN-0.42PT SC: according to data from Table 1, ratios

$$
\frac{s_{33}^{(1), E}}{s_{11}^{(1), E}}=2.71, \quad \frac{s_{11}^{(1), E}}{\left|s_{13}^{(1), E}\right|}=1.10
$$


TABLE 1: Elastic compliances $s_{a b}^{(n), E}$ (in $10^{-12} \mathrm{~Pa}^{-1}$ ), piezoelectric coefficients $d_{i j}^{(n)}$ (in pC/N), and relative dielectric permittivity $\varepsilon_{p p}^{(n), \sigma} / \varepsilon_{0}$ of single-domain SC and polymer components at room temperature.

\begin{tabular}{lccccc}
\hline Components & $s_{11}^{(n), E}$ & $s_{12}^{(n), E}$ & $s_{13}^{(n), E}$ & $s_{33}^{(n), E}$ & $s_{44}^{(n), E}$ \\
\hline PZN-0.12PT SC [8] & 20.1 & -4.6 & -18.2 & 54.5 & 19.5 \\
PMN-0.42PT SC [5] & 9.43 & -1.68 & -6.13 & 19.21 & 35.09 \\
Polyurethane [11] & 400 & -148 & -148 & 400 & 1100 \\
\hline Components & $d_{31}^{(n)}$ & $d_{33}^{(n)}$ & $d_{15}^{(n)}$ & $\varepsilon_{11}^{(n), \sigma} / \varepsilon_{0}$ & $\varepsilon_{33}^{(n), \sigma} / \varepsilon_{0}$ \\
\hline PZN-0.12PT SC [8] & -207 & 541 & 653 & 10000 & 750 \\
PMN-0.42PT SC [5] & -91 & 260 & 131 & 8627 & 660 \\
Polyurethane [11] & 0 & 0 & 0 & 3.5 & 3.5 \\
\hline
\end{tabular}

are valid for PZN-0.12PT. At the same time, the singledomain SCs are characterised by the almost equal anisotropy of $d_{3 j}^{(1)}$ : as follows from Table 1 ,

$$
\begin{aligned}
& \frac{d_{33}^{(1)}}{\left|d_{31}^{(1)}\right|}=2.61(\mathrm{PZN}-0.12 \mathrm{PT}), \\
& \frac{d_{33}^{(1)}}{\left|d_{31}^{(1)}\right|}=2.86(\mathrm{PMN}-0.42 \mathrm{PT}) .
\end{aligned}
$$

The distinctions shown in (1) could influence the piezoelectric effect and hydrostatic response of the composite, and such an effect has not been considered in detail in earlier studies. In this work, we first study the domain effects concerned with the polarisation orientation and the hydrostatic response of the 2-2 SC/polymer composite in a wide volume fraction and orientation ranges. The aim of the present paper is to show the role of the domain effects and the electromechanical properties of SCs in developing a considerable hydrostatic response of the 2-2 composite (with either single-domain or polydomain layers). Below we discuss some advantages concerned with the hydrostatic piezoelectric coefficients of the composite based on the single-domain PZN-0.12PT SC.

\section{Structure and Effective Electromechanical Properties of the 2-2 Composite}

It is assumed that the composite represents a system of the parallel-connected SC and polymer layers which form the regular laminar structure (Figure 1) with 2-2 connectivity (in terms of [9]). The crystallographic axes $X, Y$, and $Z$ of the single-domain SC in the initial state $(\alpha=0$ or $\beta=0$; see insets 1 and 2 in Figure 1 ) are parallel to the following perovskite unit-cell directions: $X\|[100]\| O X_{1}$, $Y\|[010]\| O X_{2}$, and $Z\|[001]\| O X_{3}$. In this case, the spontaneous polarization vector in each SC layer is $\mathbf{P}_{\mathbf{s}}^{(\mathbf{1})} \| O X_{3}$. We consider rotations of the $\mathbf{P}_{\mathbf{s}}^{(1)}$ vector around one of the coordinate axes- $-O X_{1}$ or $O X_{2}$ (see insets 1 and 2 in Figure 1), and all the SC layers in the composite sample have the same orientation of $\mathbf{P}_{\mathbf{s}}^{(1)}$. Thus, a system of SC cuts with a fixed orientation of the crystallographic axes $X, Y$, and $Z$ is to be prepared before manufacturing the 2-2 composite sample. The orientation of the crystallographic axes in the aligned cuts can be checked by means of X-ray technique, and the further poling procedure is assumed to be performed at the fixed orientation of the composite sample as a whole. The single-domain state of the SC layers (cuts) in the sample can be stabilised under bias. In a polydomain SC layer, the rotation of the effective spontaneous polarisation vector $\mathbf{P}_{\mathbf{s}}^{(\mathbf{1} \text {,polyd })}=m_{d} \mathbf{P}_{\mathbf{s}, \mathbf{1}}+\left(1-m_{d}\right) \mathbf{P}_{\mathbf{s}, \mathbf{2}}$ in the $\left(X_{2} O X_{3}\right)$ plane is caused by changes in the volume fraction $m_{d}$ of the laminar $90^{\circ}$ domains (inset 3 in Figure 1), and these changes can be caused by an external electric field that is initially applied to the SC layers.

The effective electromechanical properties of the 2-2 composite are studied within the framework of the matrix approach [10] that is applied to composite materials with planar microgeometry. The $9 \times 9$ matrix of the effective properties of the composite in the rectangular co-ordinate system $\left(X_{1} X_{2} X_{3}\right)$

$$
\left\|C^{*}\right\|=\left(\begin{array}{cc}
\left\|s^{* E}\right\| & \left\|d^{*}\right\|^{t} \\
\left\|d^{*}\right\| & \left\|\varepsilon^{* \sigma}\right\|
\end{array}\right)
$$

is written in terms of $\left\|s^{* E}\right\|(6 \times 6$ matrix of elastic compliances at constant electric field $),\left\|d^{*}\right\|(3 \times 6$ matrix of piezoelectric charge coefficients), and $\left\|\varepsilon^{* \sigma}\right\|(3 \times 3$ matrix of dielectric permittivities measured at constant stress), where superscript " $t$ " denotes the transposed matrix. The $\left\|C^{*}\right\|$ matrix from (3) is determined from averaging the electromechanical properties of components on the volume fraction $m$ and is given by

$$
\begin{aligned}
\left\|C^{*}\right\|= & {\left[\left\|C^{(1)}\right\| \cdot\|M\| m+\left\|C^{(2)}\right\|(1-m)\right] } \\
& \cdot[\|M\| m+\|I\|(1-m)]^{-1},
\end{aligned}
$$

where $\left\|C^{(1)}\right\|$ and $\left\|C^{(2)}\right\|$ are matrices of the electromechanical properties of SC and polymer, respectively, $\|M\|$ is concerned with the electric and mechanical boundary conditions [10] at interfaces $x_{1}=$ const (Figure 1), and $\|I\|$ is the identity $9 \times 9$ matrix. Elements of the $\left\|C^{(1)}\right\|$ matrix are written taking into account the orientation of $\mathbf{P}_{\mathbf{s}}^{(\mathbf{1})}$ in the single-domain SC layer (insets 1 and 2 in Figure 1) or the volume fraction $m_{d}$ of the $90^{\circ}$ domains (inset 3 in Figure 1). 


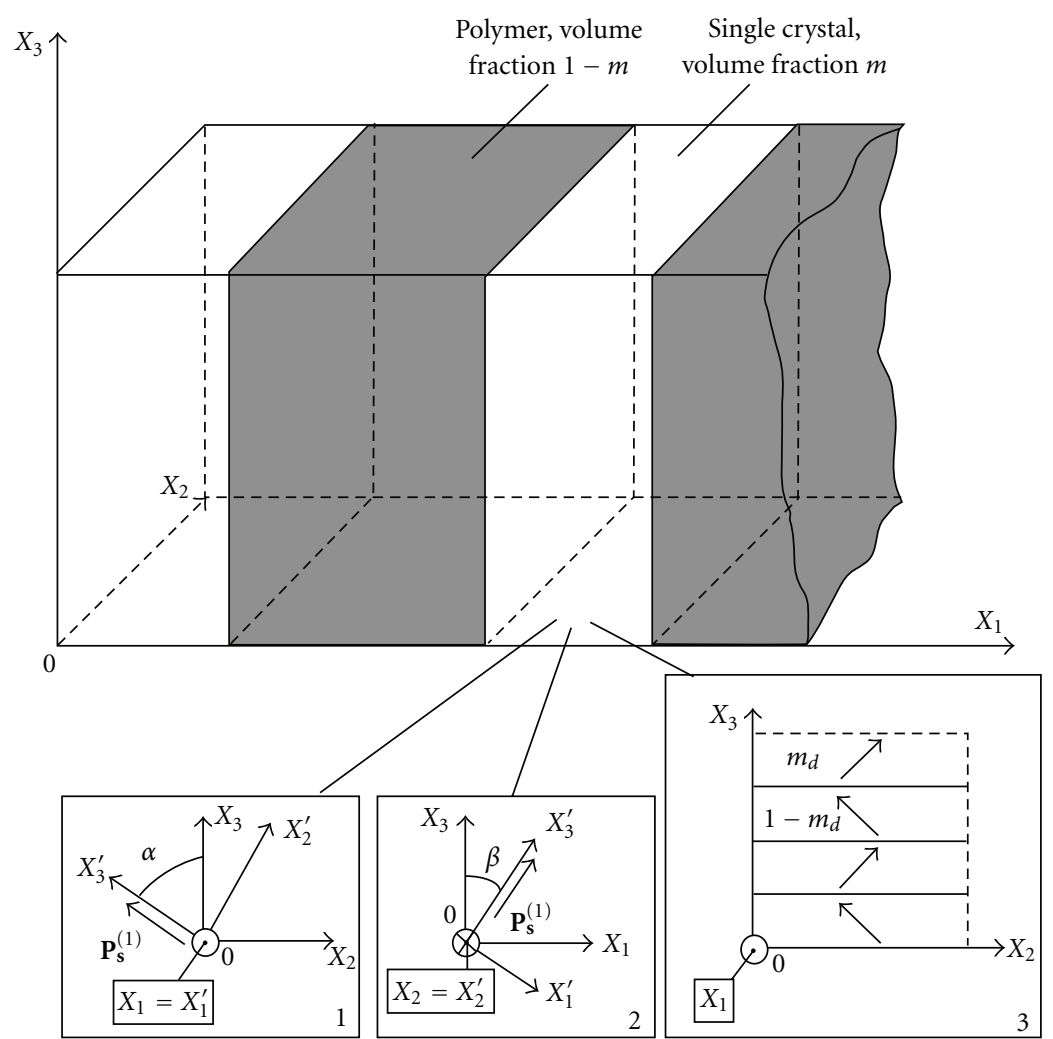

FIgURE 1: Schematic of the 2-2 parallel-connected SC/polymer composite. $\left(X_{1} X_{2} X_{3}\right)$ is the rectangular co-ordinate system of the composite sample $\alpha$ and $\beta$ are angles of rotation of the spontaneous polarisation vector $\mathbf{P}_{s}^{(1)} \| O X_{3}^{\prime}$ of the single-domain SC layer around the $O X_{1}$ axis (inset 1) or around the $\mathrm{OX}_{2}$ axis (inset 2). In inset 3 the $90^{\circ}$ domain structure in the SC layer is schematically shown, where $m_{d}$ and $1-m_{d}$ are volume fractions of the $90^{\circ}$ domains in the SC layer, and their spontaneous polarisation vectors are shown with arrows.

In case of the single-domain SC layer, the elements of $\left\|C^{(1)}\right\|$ are represented in the tensor form as $\varepsilon_{n p}^{(1), \sigma}=$ $r_{n k} r_{p l}\left(\varepsilon_{k l}^{(1), \sigma}\right)_{T}, \quad d_{i f g}^{(1)}=r_{i t} r_{f u} r_{g v}\left(d_{t u v}^{(1)}\right)_{T}$, and $s_{p q v w}^{(1), E}=$ $r_{p c} r_{q l} r_{v h} r_{w n}\left(s_{c l h n}^{(1), E}\right)_{T}$, where $r_{n k}$ is the element of the matrix that describes the rotation of the $\mathbf{P}_{\mathbf{s}}^{(1)}$ vector and the coordinate axes, and subscript " $T$ " means that the electromechanical constant is given in the main crystallographic axes, that is, taken from Table 1. The aforementioned rotation is shown in either inset 1 in Figure 1 (then $r_{n k}$ is represented in the general form as $r_{n k}=r_{n k}(\alpha)$ ) or inset 2 in Figure 1 (then in the general form $\left.r_{n k}=r_{n k}(\beta)\right)$. In the case of a polydomain SC layer (inset 3 in Figure 1), the rotation of the co-ordinate axes by $\alpha= \pm 45^{\circ}$ in the adjacent domains is to be taken into account in the matrix elements $r_{n k}, r_{p l}$, and so forth. The effective electromechanical properties of the polydomain SC layer in the co-ordinate system $\left(X_{1} X_{2} X_{3}\right)$ are determined by analogy with (4)

$$
\begin{aligned}
\left\|C^{(1)}\right\|= & {\left[\left\|C^{(d 1)}\right\| \cdot\left\|M_{d}\right\| m_{d}+\left\|C^{(d 2)}\right\|\left(1-m_{d}\right)\right] } \\
& \cdot\left[\left\|M_{d}\right\| m_{d}+\|I\|\left(1-m_{d}\right)\right]^{-1},
\end{aligned}
$$

where $\left\|C^{(d 1)}\right\|$ and $\left\|C^{(d 2)}\right\|$ are matrices of electromechanical constants of the $90^{\circ}$ domains with the volume fractions $m_{d}$ and $1-m_{d}$, respectively, and $\left\|M_{d}\right\|$ is the matrix concerned with the boundary conditions [10] for elastic and electric fields at the domain wall $x_{3}=$ const. The matrix from (5) is represented in the general form by

$$
\begin{aligned}
& \left\|C^{(1)}\right\| \\
& =\left[\begin{array}{ccccccccc}
s_{11}^{(1), E} & s_{12}^{(1), E} & s_{13}^{(1), E} & s_{14}^{(1), E} & 0 & 0 & 0 & d_{21}^{(1)} & d_{31}^{(1)} \\
s_{12}^{(1), E} & s_{22}^{(1), E} & s_{23}^{(1), E} & s_{24}^{(1), E} & 0 & 0 & 0 & d_{22}^{(1)} & d_{32}^{(1)} \\
s_{13}^{(1), E} & s_{23}^{(1), E} & s_{33}^{(1), E} & s_{34}^{(1), E} & 0 & 0 & 0 & d_{23}^{(1)} & d_{33}^{(1)} \\
s_{14}^{(1), E} & s_{24}^{(1), E} & s_{34}^{(1), E} & s_{44}^{(1), E} & 0 & 0 & 0 & d_{24}^{(1)} & d_{34}^{(1)} \\
0 & 0 & 0 & 0 & s_{55}^{(1), E} & s_{56}^{(1), E} & d_{15}^{(1)} & 0 & 0 \\
0 & 0 & 0 & 0 & s_{56}^{(1), E} & s_{66}^{(1), E} & d_{16}^{(1)} & 0 & 0 \\
0 & 0 & 0 & 0 & d_{15}^{(1)} & d_{16}^{(1)} & \varepsilon_{11}^{(1), \sigma} & 0 & 0 \\
d_{21}^{(1)} & d_{22}^{(1)} & d_{23}^{(1)} & d_{24}^{(1)} & 0 & 0 & 0 & \varepsilon_{22}^{(1), \sigma} & \varepsilon_{23}^{(1), \sigma} \\
d_{31}^{(1)} & d_{32}^{(1)} & d_{33}^{(1)} & d_{34}^{(1)} & 0 & 0 & 0 & \varepsilon_{23}^{(1), \sigma} & \varepsilon_{33}^{(1), \sigma}
\end{array}\right] .
\end{aligned}
$$

It should be added that the electromechanical properties of the polydomain PZN-0.12PT SC were also calculated in [8]. 
The $\|M\|$ matrix from (4) is determined [10] with due regard for the boundary conditions at the layer interfaces $x_{1}=$ const as follows: $\|M\|=\left\|W_{1}\right\|^{-1} \cdot\left\|W_{2}\right\|$, where

$$
\begin{aligned}
& \left\|W_{n}\right\| \\
& =\left[\begin{array}{ccccccccc}
1 & 0 & 0 & 0 & 0 & 0 & 0 & 0 & 0 \\
s_{12}^{(n), E} & s_{22}^{(n), E} & s_{23}^{(n), E} & s_{24}^{(n), E} & s_{25}^{(n), E} & s_{26}^{(n), E} & d_{12}^{(n)} & d_{22}^{(n)} & d_{32}^{(n)} \\
s_{13}^{(n), E} & s_{23}^{(n), E} & s_{33}^{(n), E} & s_{34}^{(n), E} & s_{35}^{(n), E} & s_{36}^{(n), E} & d_{13}^{(n)} & d_{23}^{(n)} & d_{33}^{(n)} \\
s_{14}^{(n), E} & s_{24}^{(n), E} & s_{34}^{(n), E} & s_{44}^{(n), E} & s_{45}^{(n), E} & s_{46}^{(n), E} & d_{14}^{(n)} & d_{24}^{(n)} & d_{34}^{(n)} \\
0 & 0 & 0 & 0 & 1 & 0 & 0 & 0 & 0 \\
0 & 0 & 0 & 0 & 0 & 1 & 0 & 0 & 0 \\
d_{11}^{(n)} & d_{12}^{(n)} & d_{13}^{(n)} & d_{14}^{(n)} & d_{15}^{(n)} & d_{16}^{(n)} & \varepsilon_{11}^{(n), \sigma} & \varepsilon_{12}^{(n), \sigma} & \varepsilon_{13}^{(n), \sigma} \\
0 & 0 & 0 & 0 & 0 & 0 & 0 & 1 & 0 \\
0 & 0 & 0 & 0 & 0 & 0 & 0 & 0 & 1
\end{array}\right],
\end{aligned}
$$

$n=1$ is related to SC, and $n=2$ is related to polymer. The effective electromechanical properties of the composite ( $\left\|C^{*}\right\|$ from (4)) and the polydomain layer $\left(\left\|C^{(1)}\right\|\right.$ from (5)) are determined on an assumption that the wavelengths of acoustic waves propagated are considerably longer than the thickness of each layer in the composite sample (Figure 1), and the thickness of each domain (see inset 3 in Figure 1) is much less than the height of the polydomain layer.

Based on matrix elements of $\left\|C^{*}\right\|$ from (4), we study the volume fraction and orientation dependences of the hydrostatic piezoelectric coefficients

$$
\begin{aligned}
& d_{h}^{*}=d_{31}^{*}+d_{32}^{*}+d_{33}^{*}, \\
& g_{h}^{*}=g_{31}^{*}+g_{32}^{*}+g_{33}^{*}, \\
& e_{h}^{*}=e_{31}^{*}+e_{32}^{*}+e_{33}^{*},
\end{aligned}
$$

and hydrostatic electromechanical coupling factor of the composite

$$
k_{h}^{*}=\frac{d_{h}^{*}}{\sqrt{s_{h}^{* E} \varepsilon_{33}^{* \sigma}}} .
$$

The piezoelectric coefficients $g_{i j}^{*}$ from (8) are determined from the matrix $\left\|g^{*}\right\|=\left\|d^{*}\right\| \cdot\left\|\varepsilon^{* \sigma}\right\|^{-1}$ the piezoelectric coefficients $e_{i j}^{*}$ from (8) are determined from the matrix $\left\|e^{*}\right\|=\left\|d^{*}\right\| \cdot\left\|s^{* E}\right\|^{-1}$. Hydrostatic compliance $s_{h}^{* E}$ of the composite at $E=$ const (see (9)) is defined as follows: $s_{h}^{* E}=\sum_{a=1}^{3} \sum_{b=1}^{3} s_{a b}^{* E}$. The hydrostatic parameters $\Phi_{h}^{*}$ from (8) and (9) characterise the performance of the composite sample (Figure 1) with electrodes that are parallel to the $\left(X_{1} O X_{2}\right)$ plane. The effective electromechanical properties of the polydomain SC layer (inset 3, Figure 1), the composite as a whole (see (4)), and its hydrostatic parameters (see (8) and (9)) are calculated using the full sets of experimental electromechanical constants from Table 1.

\section{Hydrostatic Parameters and Advantages}

Examples of the calculated volume-fraction and orientation dependences of the hydrostatic parameters $\Phi_{h}^{*}$ of the composite based on the single-domain PZN-0.12PT SC are shown in Figures 2 and 3. The presence of SC with $4 \mathrm{~mm}$ symmetry and polymer with $\infty \mathrm{mm}$ symmetry enables us to establish the periodic dependence of the hydrostatic parameters on the rotation angles $\alpha$ and $\beta$. For any value of $m$ from the range $0<m<1$, the equalities $\Phi_{h}^{*}(m, \alpha)=$ $\Phi_{h}^{*}\left(m, 180^{\circ}-\alpha\right)$ and $\Phi_{h}^{*}(m, \beta)=\Phi_{h}^{*}(m,-\beta)$ hold, where $0^{\circ} \leq \alpha<90^{\circ}$ and $0^{\circ} \leq \beta<90^{\circ}$.

Changes in the orientation of the $\mathbf{P}_{\mathbf{s}}^{(1)}$ vector of the SC layer in the $\left(\mathrm{X}_{2} \mathrm{OX}_{3}\right)$ plane (inset 1 in Figure 1) mean changes in projections of $\mathbf{P}_{\mathbf{s}}^{(\mathbf{1})}$ on the $\mathrm{OX}_{2}$ and $\mathrm{OX}_{3}$ axes, along which both the components of the composite are distributed continuously. Such a mode of rotation of the $\mathbf{P}_{\mathbf{s}}^{(1)}$ vector leads to a relatively smooth dependence of the hydrostatic parameters $\Phi_{h}^{*}$ on $\alpha$ (Figure 2). The hydrostatic piezoelectric coefficient $d_{h}^{*}$ of the composite (Figure 2(a)) remains less than $d_{h}^{(1)}$ of the single-domain SC. A combination of the piezoelectric $\left(d_{i j}^{*}\right)$ and dielectric $\left(\varepsilon_{p p}^{* \sigma}\right)$ properties gives rise to the pronounced maxima of $g_{h}^{*}$ at $\alpha=$ const (Figure 2(b)) however, these maxima take place at a small volume fraction $m$. In (Figure 2(b)), we omit the volumefraction range $0.1<m<1$ where $g_{h}^{*}$ monotonically decreases at $\alpha=$ const. Combining the piezoelectric $\left(d_{i j}^{*}\right)$ and elastic $\left(s_{a b}^{* E}\right)$ properties, one can attain the nonmonotonic volume-fraction behaviour of the hydrostatic piezoelectric coefficient $e_{h}^{*}$ (Figure 2(c)) however, values of $e_{h}^{*}$ near the local maximum points are relatively small. The complicated shape of the surface of $k_{h}^{*}(m, \alpha)$ (Figure $\left.2(\mathrm{~d})\right)$ is a result of the active influence of the dielectric properties at $0<m<0.1$ and of the elastic properties at $0.4<m<0.9$. As follows from the comparison of the $k_{h}^{*}(m, \alpha)$ and $d_{h}^{*}(m, \alpha)$ dependences, there is a correlation between them in certain ranges of $m$ and $\alpha$. It should be noted that this correlation stems from (9) and is concerned with the relatively smooth dependence of $s_{h}^{* E}$ and $\varepsilon_{33}^{* \sigma}$ on $m$ and $\alpha$.

The related composite based on the polydomain SC (see inset 3 in Figure 1) is characterised by the hydrostatic parameters varying in the fairly narrow ranges (Table 2 ). The polydomain SC layers have fixed orientations and volume fractions $\left(m_{d}\right.$ and $\left.1-m_{d}\right)$ of the $90^{\circ}$ domains over the whole composite sample, and a change in $m_{d}$ means a rotation of the effective spontaneous polarisation vector $\mathbf{P}_{\mathbf{s}}^{(\mathbf{1} \text {, polyd })}$ in the $\left(\mathrm{X}_{2} O X_{3}\right)$ plane. As in the previous case of the single-domain SC layer, this rotation does not lead to considerable hydrostatic parameters. In our evaluations, the $90^{\circ}$ domain walls of the polydomain SC layer are assumed to be motionless. A contribution from the $90^{\circ}$ domain-wall displacements [12] provides a contribution into electromechanical constants of SC. Our estimations show that this domain-wall contribution might give rise to 


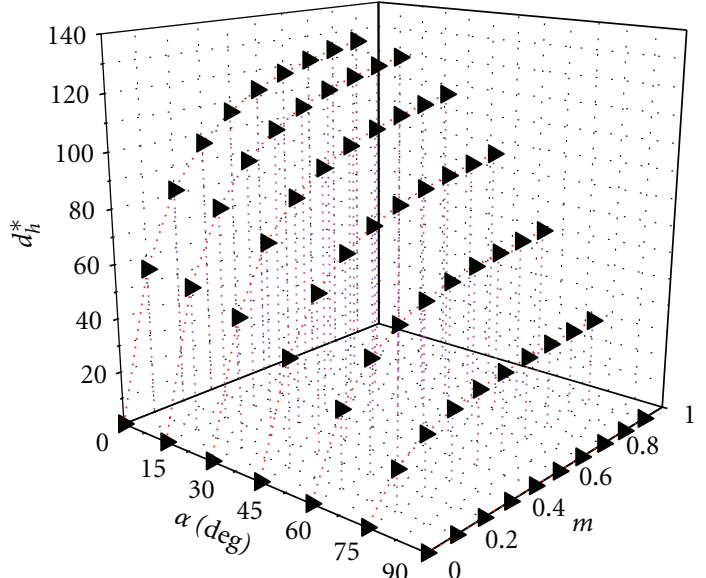

(a)

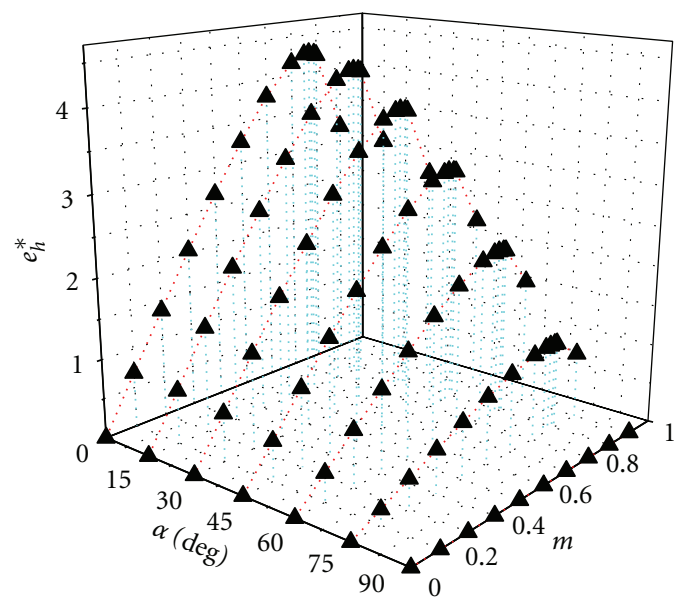

(c)

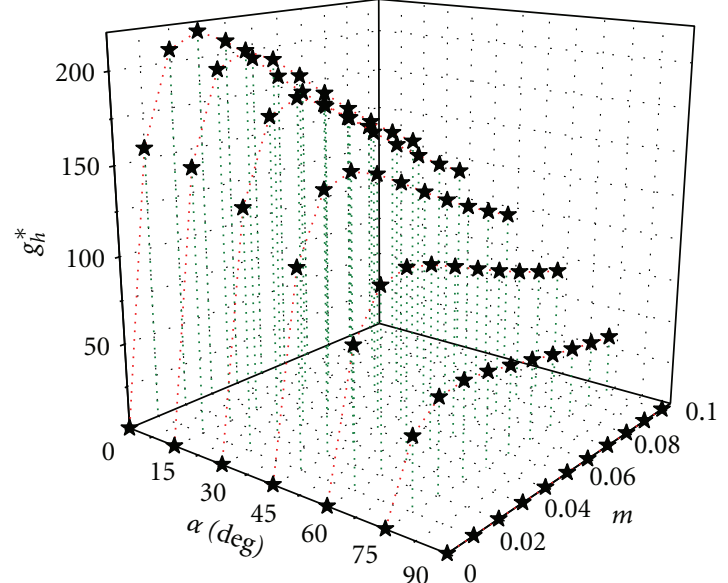

(b)

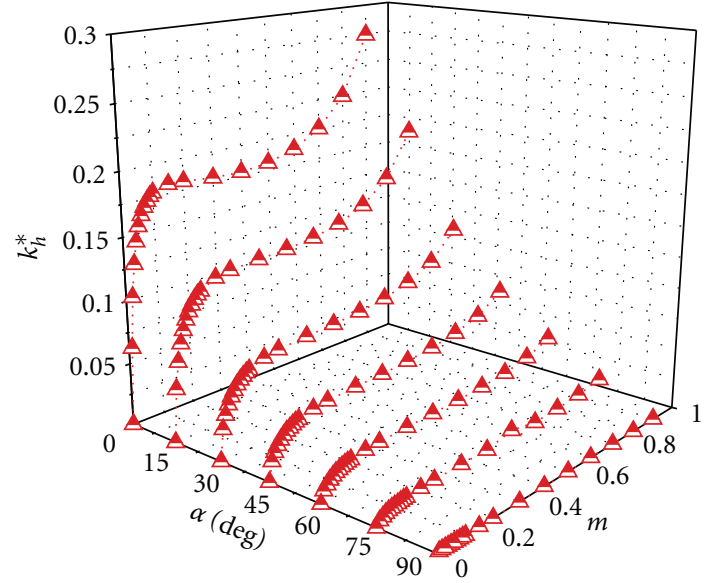

(d)

FIgure 2: Hydrostatic piezoelectric coefficients (a)-(c) and electromechanical coupling factor (d) of the PZN-0.12PT SC/polyurethane composite at the rotation of the spontaneous polarisation vector $\mathbf{P}_{\mathbf{s}}^{(1)}$ of the single-domain SC layer around the $O X_{1}$ axis (see inset 1 in Figure 1): (a) $d_{h}^{*}($ in $\mathrm{pC} / \mathrm{N}),(\mathrm{b}) g_{h}^{*}($ in $\mathrm{mV} \cdot \mathrm{m} / \mathrm{N}),(\mathrm{c}) e_{h}^{*}\left(\right.$ in $\left.\mathrm{C} / \mathrm{m}^{2}\right)$, and (d) $k_{h}^{*}$.

increasing the upper bounds on $\Phi_{h}^{*}$ (Table 2) by about $1.5-2$ times.

Varying the angle $\beta$ means the crossing of the spontaneous polarisation vector $\mathbf{P}_{\mathbf{s}}^{(1)}$ of the single-domain SC layer and the interface $x_{1}=$ const (see inset 2 in Figure 1). This mode of rotation of $\mathbf{P}_{\mathbf{s}}^{(\mathbf{1})}$ becomes favourable to achieve large values of hydrostatic parameters $\Phi_{h}^{*}(m, \beta)$ (Figure 3 ). In addition to the aforementioned combination of the electromechanical properties, the anisotropy of elastic compliances $s_{a b}^{(1), E}$ of SC leads to increasing $\Phi_{h}^{*}$ in different volume-fraction ranges. Of particular interest is the hydrostatic piezoelectric coefficient $e_{h}^{*}(m, \beta)$ (Figure 3(c)) with the deep absolute minimum. Recently [4], absolute $\min e_{h}^{*}=-44.4 \mathrm{C} / \mathrm{m}^{2}$ was found for the 2-2 PMN-0.33PT SC/polyvinylidene fluoride composite with the singledomain SC and piezo-active polymer layers. Distinctions between PMN-0.33PT and PZN-0.12PT (both SCs in the single-domain state) are associated with both symmetry
$[7,8]$ and anisotropy of the electromechanical properties. As follows from experimental data on single-domain PMN0.33PT SCs with $3 \mathrm{~m}$ symmetry [7], the ratios $s_{11}^{(1), E} / s_{13}^{(1), E}=$ $-11.1, s_{11}^{(1), E} / s_{33}^{(1), E}=4.68$, and $d_{22}^{(1)} / d_{33}^{(1)}=7.05$ hold in the main crystallographic axes. The above circumstances are to be taken into account when comparing the composite performance. Undoubtedly, values of $\left|e_{h}^{*}\right| \approx 77 \mathrm{C} / \mathrm{m}^{2}$ (Figure 3(c)) enable us to regard the studied 2-2 composite as an outstanding piezoelectric material for hydroacoustic applications. To the best of our knowledge, in various ferroelectric ceramic/polymer composites [10], the typical $e_{h}^{*}$ values do not exceed $14 \mathrm{C} / \mathrm{m}^{2}$, and values of $\mathrm{e}_{h}^{*} \approx 10 \mathrm{C} / \mathrm{m}^{2}$ are peculiar to conventional poled ferroelectric ceramics at room temperature $[10,13]$.

Our comparison of the performance of the composites based on single-domain SCs of PZN-0.12PT and PMN$0.42 \mathrm{PT}$ SCs (Table 3) suggests that the main difference between the hydrostatic parameters of these composites is associated with the piezoelectric coefficients of the SCs 


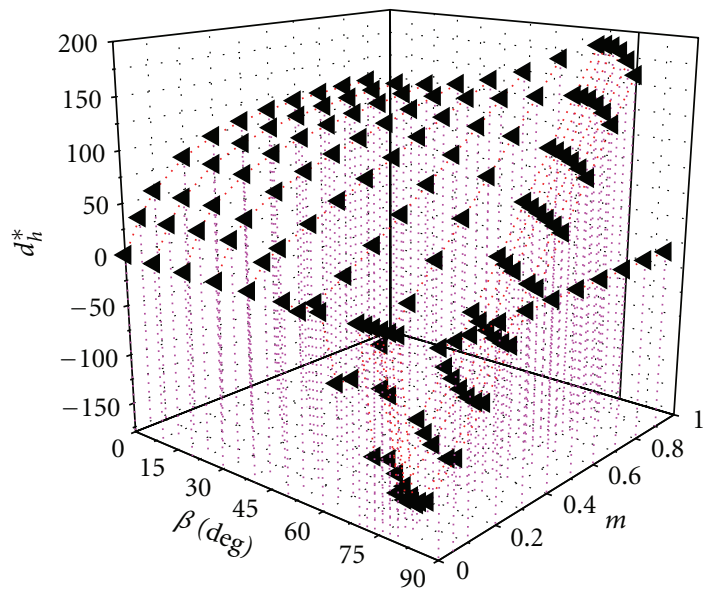

(a)

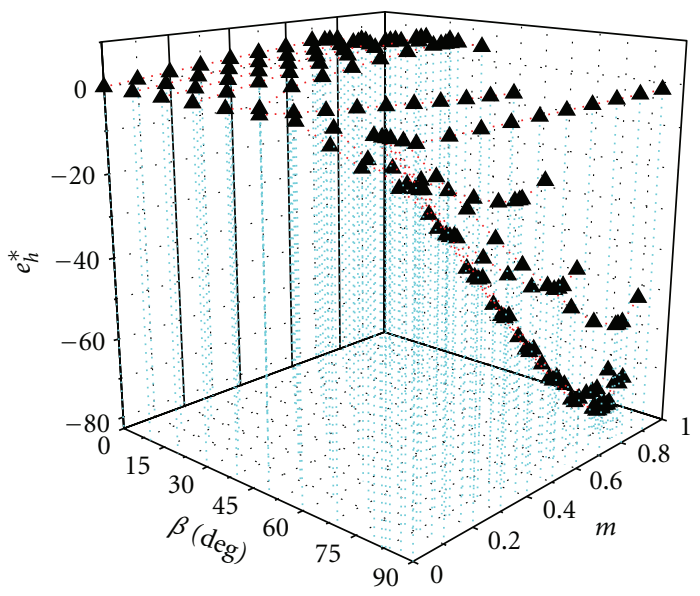

(c)

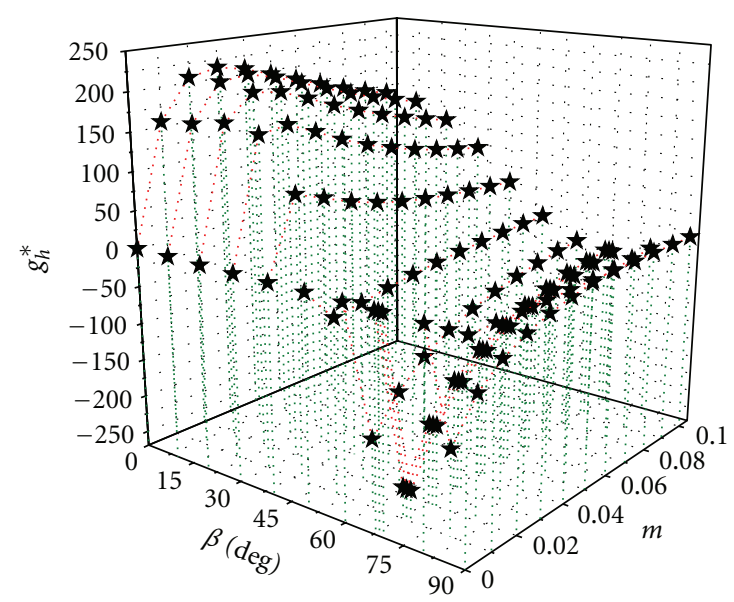

(b)

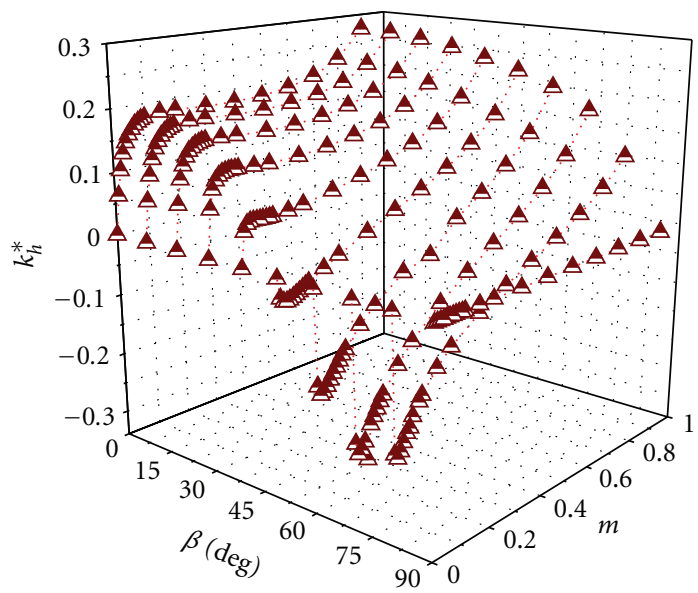

(d)

Figure 3: Hydrostatic piezoelectric coefficients (a)-(c) and electromechanical coupling factor (d) of the PZN-0.12PT SC/polyurethane composite at the rotation of the spontaneous polarisation vector $\mathbf{P}_{s}^{(1)}$ of the single-domain SC layer around the $O X_{2}$ axis (see inset 2 in Figure 1): (a) $d_{h}^{*}($ in $\mathrm{pC} / \mathrm{N}),(\mathrm{b}) g_{h}^{*}($ in $\mathrm{mV} \cdot \mathrm{m} / \mathrm{N}),(\mathrm{c}) e_{h}^{*}\left(\right.$ in $\left.\mathrm{C} / \mathrm{m}^{2}\right)$, and $(\mathrm{d}) k_{h}^{*}$.

TABLE 2: Lower and upper bounds on hydrostatic parameters $\Phi_{h}^{*}\left(m, m_{d}\right)$ of the PZN-0.12PT SC/polyurethane composite with polydomain SC layers (see inset 3 in Figure 1 ) at $0<m<1$ and $m_{d}=$ const.

\begin{tabular}{lccr}
\hline$\Phi_{h}^{*}$ & $m_{d}=0.1$ and $m_{d}=0.9$ & $m_{d}=0.3$ and $m_{d}=0.7$ & $m_{d}=0.5$ \\
\hline$d_{h}^{*}($ in $\mathrm{pC} / \mathrm{N})$ & $0<d_{h}^{*}<89.8$ & $0<d_{h}^{*}<89.8$ & $0<d_{h}^{*}<89.8$ \\
$\mathrm{~g}_{h}^{*}($ in $\mathrm{mV} \cdot \mathrm{m} / \mathrm{N})$ & $0<g_{h}^{*}<10.6$ & $0<g_{h}^{*}<4.68$ & $0<g_{h}^{*}<1.89$ \\
$e_{h}^{*}\left(\right.$ in $\left.\mathrm{C} / \mathrm{m}^{2}\right)$ & $-0.816<e_{h}^{*}<0.763$ & $0<e_{h}^{*}<7.81$ & $0<e_{h}^{*}<10.5$ \\
$k_{h}^{*}$ & $0<k_{h}^{*}<0.115$ & $0<k_{h}^{*}<0.115$ & $0<k_{h}^{*}<0.115$ \\
\hline
\end{tabular}

(Table 1). In addition, the hydrostatic piezoelectric coefficient $g_{h}^{*}$ (see Table 3 and Figures 2(b) and 3(b)) at small volume fractions $(0<m<0.1)$ strongly depends on the dielectric properties of components, while the hydrostatic piezoelectric coefficient $e_{h}^{*}$ mainly depends on the anisotropy of the elastic properties of SC. It is clear that the anisotropy of elastic compliances $s_{a b}^{(1), E}$ of the single-domain PMN-0.42PT $\mathrm{SC}$ is less pronounced (Table 1 ) and therefore do not lead to the very large $\left|e_{h}^{*}\right|$ values in the composite based on this SC. As for the extreme values of $g_{h}^{*}$, they are achieved at small volume fractions $m$ and are of the same order of magnitude as those studied in earlier papers $[1,3,4,10]$.

We also reveal an interesting correlation between the volume-fraction dependences of the hydrostatic piezoelectric coefficients and the piezoelectric coefficients that contribute to the hydrostatic response of the composite based on 
TABle 3: Extreme values of hydrostatic parameters $\Phi_{h}^{*}(m, \beta)$ of 2-2 composites with single-domain SC layers (see inset 2 in Figure 1) at $0<m<1$ and $0^{\circ} \leq \beta \leq 90^{\circ}$.

\begin{tabular}{|c|c|c|c|c|}
\hline \multirow{2}{*}{ Parameter } & \multicolumn{2}{|c|}{ Single-domain PZN-0.12PT SC/polyurethane composite } & \multicolumn{2}{|c|}{ Single-domain PMN-0.42PT SC/polyurethane composite } \\
\hline & Absolute minima & Absolute maxima & Absolute minima & Absolute maxima \\
\hline$d_{h}^{*}$ & $\begin{array}{l}-161 \mathrm{pC} / \mathrm{N} \text { at } m=0.090 \\
\text { and } \beta=78^{\circ}\end{array}$ & $\begin{array}{l}214 \mathrm{pC} / \mathrm{N} \text { at } m=0.972 \\
\text { and } \beta=72^{\circ}\end{array}$ & $\begin{array}{l}-69.9 \mathrm{pC} / \mathrm{N} \text { at } m=0.081 \\
\text { and } \beta=78^{\circ}\end{array}$ & $\begin{array}{l}130 \mathrm{pC} / \mathrm{N} \text { at } m=0.968 \\
\text { and } \beta=72^{\circ}\end{array}$ \\
\hline$g_{h}^{*}$ & $\begin{array}{l}-261 \mathrm{mV} \cdot \mathrm{m} / \mathrm{N} \text { at } m= \\
0.005 \text { and } \beta=71^{\circ}\end{array}$ & $\begin{array}{l}215 \mathrm{mV} \cdot \mathrm{m} / \mathrm{N} \text { at } m=0.028 \\
\text { and } \beta=0^{\circ}\end{array}$ & $\begin{array}{l}-821 \mathrm{mV} \cdot \mathrm{m} / \mathrm{N} \text { at } m=0.005 \\
\text { and } \beta=70^{\circ}\end{array}$ & $\begin{array}{l}197 \mathrm{mV} \cdot \mathrm{m} / \mathrm{N} \text { at } m=0.017 \\
\text { and } \beta=0^{\circ}\end{array}$ \\
\hline$e_{h}^{*}$ & $\begin{array}{l}-77.2 \mathrm{C} / \mathrm{m}^{2} \text { at } m=0.825 \\
\text { and } \beta=83^{\circ}\end{array}$ & $\begin{array}{l}7.78 \mathrm{C} / \mathrm{m}^{2} \text { at } m=0.768 \\
\text { and } \beta=35^{\circ}\end{array}$ & $\begin{array}{l}-28.6 \mathrm{C} / \mathrm{m}^{2} \text { at } m=0.725 \\
\text { and } \beta=79^{\circ}\end{array}$ & $\begin{array}{l}10.2 \mathrm{C} / \mathrm{m}^{2} \text { at } m=0.931 \\
\text { and } \beta=0^{\circ}\end{array}$ \\
\hline$k_{h}^{*}$ & $\begin{array}{l}-0.237 \text { at } m=0.020 \\
\text { and } \beta=74^{\circ}\end{array}$ & $-^{\mathrm{a}}$ & $\begin{array}{l}-0.100 \text { at } m=0.025 \\
\text { and } \beta=74^{\circ}\end{array}$ & $\begin{array}{l}0.144 \text { at } m=0.063 \\
\text { and } \beta=0^{\circ}\end{array}$ \\
\hline
\end{tabular}

${ }^{\mathrm{a}}$ The largest value of $k_{h}^{*}$ corresponds to SC $(m=1)$.

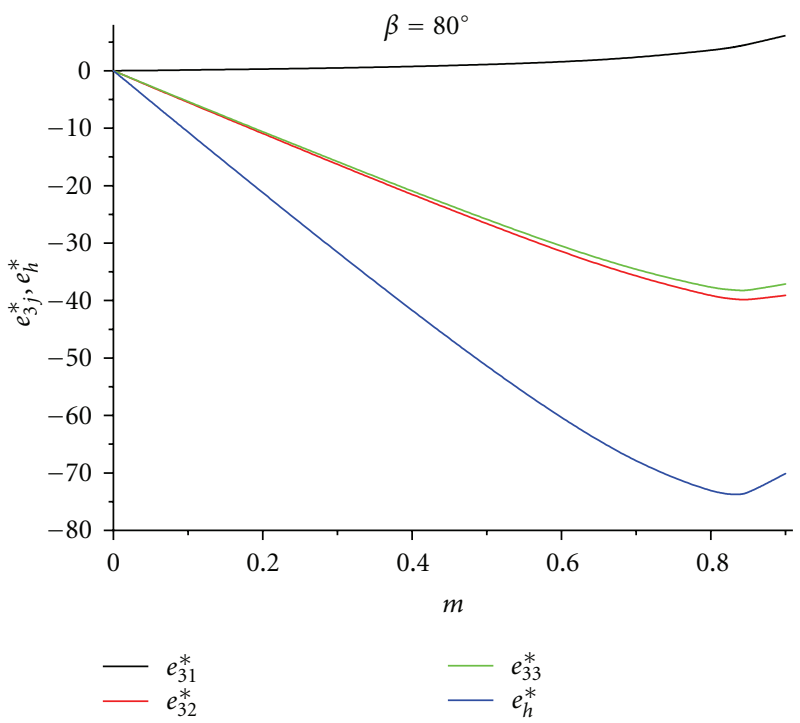

(a)

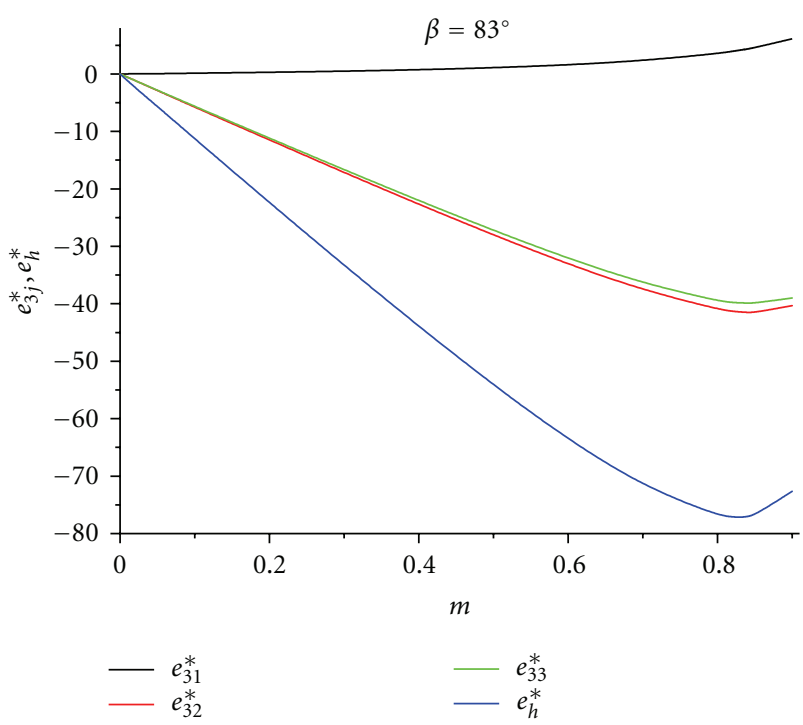

(b)

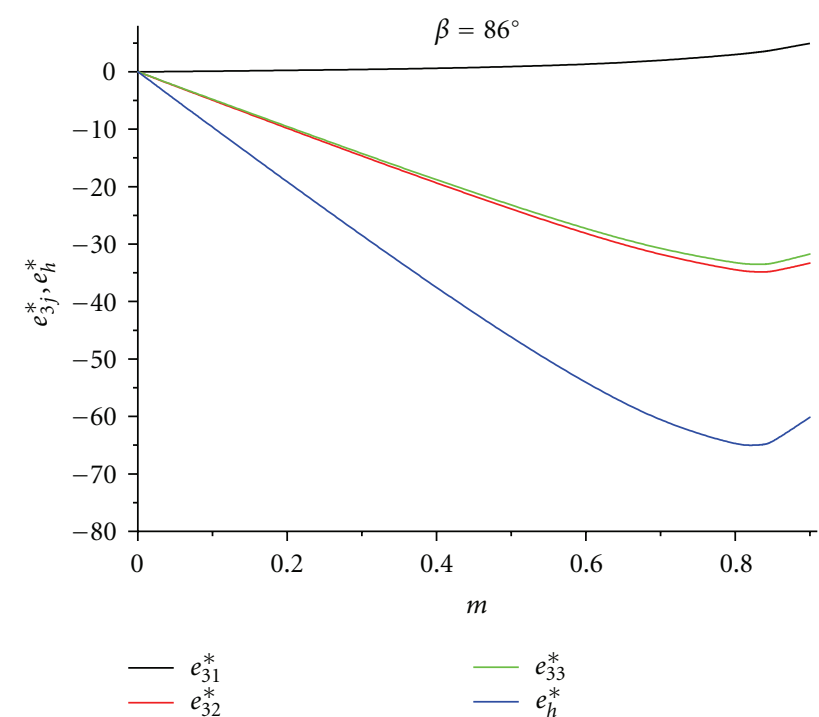

(c)

Figure 4: Correlation between piezoelectric coefficients $e_{3 j}^{*}$ and $e_{h}^{*}\left(\right.$ in $\mathrm{C} / \mathrm{m}^{2}$ ) of the PZN-0.12PT SC/polyurethane composite near absolute $\min e_{h}^{*}$. The spontaneous polarisation vector $\mathbf{P}_{\mathrm{s}}^{(1)}$ of the single-domain SC layer is oriented as shown in inset 2 in Figure 1, the rotation angle $\beta=80^{\circ}$ (a), $83^{\circ}$ (b) and $86^{\circ}$ (c). 


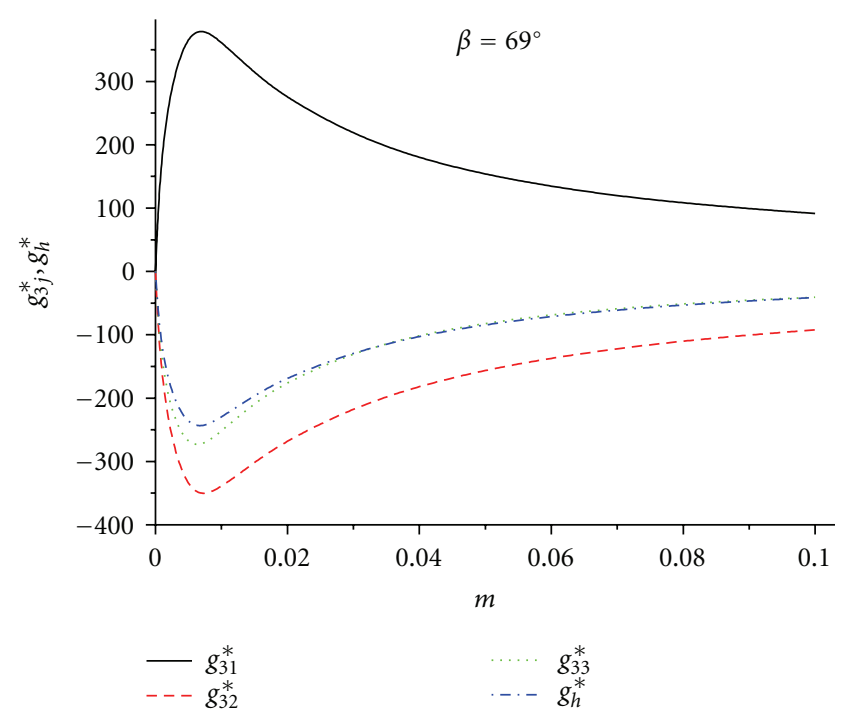

(a)

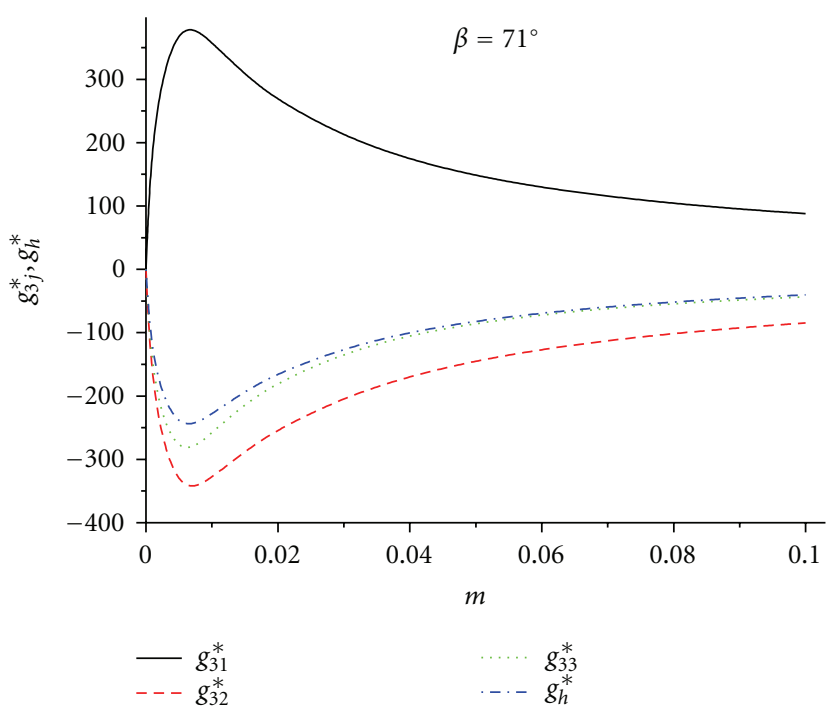

(b)

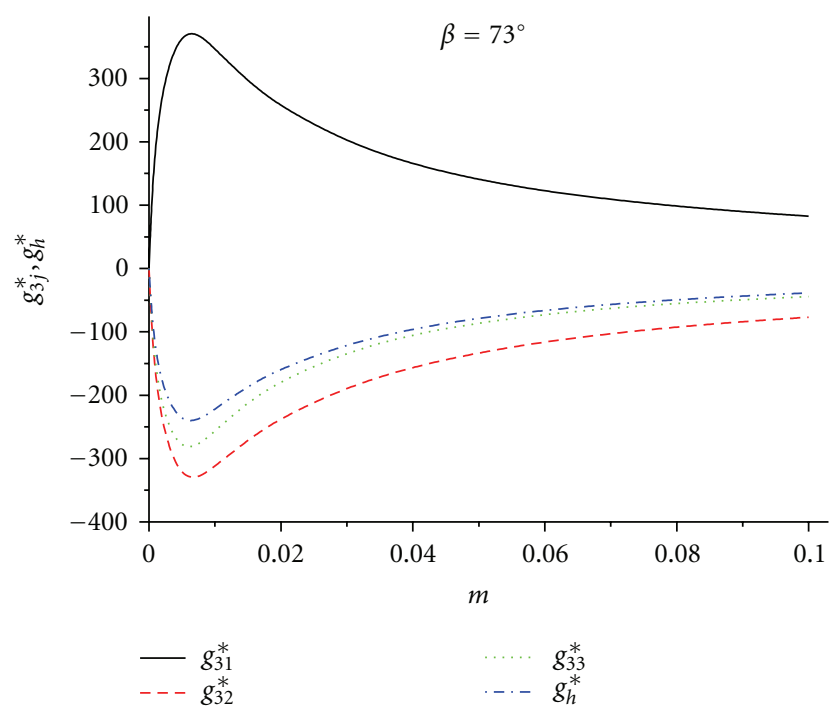

(c)

FIGURE 5: Correlation between piezoelectric coefficients $g_{3 j}^{*}$ and $g_{h}^{*}$ (in $\mathrm{mV} \cdot \mathrm{m} / \mathrm{N}$ ) of the PZN-0.12PT SC/polyurethane composite near absolute $\min g_{h}^{*}$. The spontaneous polarisation vector $\mathbf{P}_{\mathbf{s}}^{(1)}$ of the single-domain SC layer is oriented as shown in inset 2 in Figure 1 , the rotation angle $\beta=69^{\circ}$ (a), $71^{\circ}$ (b) and $73^{\circ}$ (c).

PZN-0.12PT SC (see (8) and Figures 4 and 5). Graphs in Figure 4 show that, near the absolute minimum of $e_{h}^{*}$, the piezoelectric coefficients $e_{3 j}^{*}$ from (8) obey conditions

$$
e_{32}^{*} \approx e_{33}^{*}, \quad\left|e_{33}^{*}\right| \gg e_{31}^{*},
$$

that is, the presence of interfaces $x_{1}=$ const weakens the electromechanical interaction between the SC layers (Figure 1) and strongly influences the anisotropy of $e_{3 j}^{*}$. Contrary to $e_{3 j}^{*}$ from Figure 4, the piezoelectric coefficients $g_{3 j}^{*}$ from Figure 5 obey conditions

$$
g_{31}^{*} \approx\left|g_{32}^{*}\right|, \quad g_{33}^{*} \approx g_{h}^{*} .
$$

In our opinion, the distinctions between conditions (10) and (11) are associated with the different volume-fraction ranges of validity (e.g., large $m$ values for $e_{3 j}^{*}$ and small $m$ values for $g_{3 j}^{*}$ ) and with the combination of the properties in the 2-2 parallel-connected composite. In case of $e_{3 j}^{*}$, the combination of the piezoelectric and elastic properties plays the leading role, whereas behaviour of $g_{3 j}^{*}$ is accounted for by the combination of the piezoelectric and dielectric properties. Graphs in Figure 5 suggest that large $\left|g_{h}^{*}\right|$ values can be attained at volume fractions of SC $m \approx 0.04-0.07$, and this range is to be taken into consideration when manufacturing the composite sample with high piezoelectric sensitivity. Our analysis of behaviour of the piezoelectric coefficients near the absolute maxima (Figures 4 and 5) enables us to conclude 
that not only the elastic and dielectric anisotropy, but also the parallel interfaces $x_{1}=$ const in the composite sample influence validity of conditions (10) and (11) in certain volume-fraction and orientation ranges.

\section{Conclusion}

In this paper, we first studied features of the hydrostatic piezoelectric response of the novel 2-2 PZN-0.12PT $\mathrm{SC} /$ polyurethane composite with parallel-connected layers. The considerable hydrostatic parameters and the anisotropy of the piezoelectric coefficients (see conditions (10) and (11)) in the composite based on the single-domain PZN-0.12PT SC are strongly connected with peculiarities of its elastic and piezoelectric properties as well as with the orientation of the spontaneous polarisation vector $\mathbf{P}_{\mathbf{s}}^{(1)}$ with respect to the interface $x_{1}=$ const (Figure 1). The correlation between the piezoelectric coefficients near the absolute minima of the hydrostatic parameters (Figures 4 and 5 ) is observed at different conditions for the piezoelectric coefficients (cf. (10) and (11)), and such behaviour has no analogs among other piezo-active composites. In our opinion, the anisotropy of the piezoelectric and elastic properties of the singledomain SC indirectly could influence the volume-fraction dependence of the piezoelectric coefficients shown in Figures 4 and 5.

The orientation effect studied in this paper enables us to conclude that the mutual arrangement of the interfaces and the spontaneous polarisation vectors of the SC layers (Figure 1) plays an important role in forming the significant hydrostatic response of the 2-2 parallel-connected composite. The single-domain SC layers in the 2-2 composite studied have advantages over the polydomain layers mainly as the result of the large hydrostatic piezoelectric coefficients from (8). According to data from Table 3 and Figure 3, and values of $d_{h}^{*} \approx 200 \mathrm{pC} / \mathrm{N}$ are expected at $0.90<m<0.98$ and $70^{\circ}<\beta<75^{\circ}$, values of $\left|g_{h}^{*}\right| \approx 200 \mathrm{mV} \cdot \mathrm{m} / \mathrm{N}$ are predicted for $m \approx 0.04-0.07$ and $70^{\circ}<\beta<75^{\circ}$ (more preferable) or for $m \approx 0.03-0.04$ and $\beta=0^{\circ}$ (less preferable because of the lower volume fraction $m$ of SC). It is remarkable that these hydrostatic parameters attain the extreme values in the same narrow range of the orientation angle $\beta$. The value of absolute min $e_{h}^{*}=-77.2 \mathrm{C} / \mathrm{m}^{2}$ is achieved at $m=$ 0.825 and $\beta=83^{\circ}$. Moreover, near this minimum point, conditions (10) are valid for the piezoelectric coefficients $e_{3 j}^{*}$ (Figure 4) that bring contributions into $e_{h}^{*}$ from (8). As for the variation of the $\alpha$ angle (inset 1 in Figure 1) and the volume fraction $m_{d}$ of the $90^{\circ}$ domains shown in inset 3 in Figure 1, it leads to the smaller extreme values of the effective hydrostatic parameters from (8) and (9). In our opinion, such a suppression of the hydrostatic response in comparison with that at the variation of the $\beta$ angle is directly connected with peculiarities of the elastic and piezoelectric anisotropy of the single-domain PZN-0.12PT SC.

The hydrostatic piezoelectric performance and the piezoelectric anisotropy of the studied composite based on the single-domain PZN-0.12PT SC is of value for specialists manufacturing the advanced composites with pronounced domain effects. The results reported and discussed in the present paper may stimulate new studies on interrelations between the electromechanical properties of anisotropic components and the performance of the novel piezo-active composites.

\section{Acknowledgments}

The authors wish to thank professor Dr. A. E. Panich and professor Dr. I.A. Parinov (Rostov-on-Don, Russia), Dr. C. R. Bowen (Bath, UK), and professor Dr. P. Bisegna (Rome, Italy) for their interest in the research problems. The authors are also grateful to Dr. C. R. Bowen (Bath, UK) for his careful reading of the paper of the present publication. This work was partially supported by the administration of the Southern Federal University (Project no. 11.1.09f on basic research), and this support is gratefully acknowledged.

\section{References}

[1] A. V. Krivoruchko and V. Yu. Topolov, "On the remarkable performance of novel 2-2-type composites based on [011] poled $0.93 \mathrm{~Pb}\left(\mathrm{Zn}_{1 / 3} \mathrm{Nb}_{2 / 3}\right) \mathrm{O}_{3}-0.07 \mathrm{PbTiO}_{3}$ single crystals," Journal of Physics D, vol. 40, no. 22, pp. 7113-7120, 2007.

[2] V. Yu. Topolov, A. V. Krivoruchko, P. Bisegna, and C. R. Bowen, "Orientation effects in 1-3 composites based on $0.93 \mathrm{~Pb}\left(\mathrm{Zn}_{1 / 3} \mathrm{Nb}_{2 / 3}\right) \mathrm{O}_{-3}-0.07 \mathrm{PbTiO}_{3}$ single crystals," Ferroelectrics, vol. 376, no. 1, pp. 140-152, 2008.

[3] V. Yu. Topolov and A. V. Krivoruchko, "Orientation effects in 2-2 piezocomposites based on $(1-x) \mathrm{Pb}\left(\mathrm{A}_{1 / 3} \mathrm{Nb}_{2 / 3}\right) \mathrm{O}_{3}$ $-x \mathrm{PbTiO}_{3}$ single crystals $(A=\mathrm{Mg}$ or $\mathrm{Zn})$," Journal of Applied Physics, vol. 105, no. 7, Article ID 074105, 7 pages, 2009.

[4] V. Yu. Topolov and A. V. Krivoruchko, "Polarization orientation effect and combination of electromechanical properties in advanced $0.67 \mathrm{~Pb}\left(\mathrm{Mg}_{1 / 3} \mathrm{Nb}_{2 / 3}\right) \mathrm{O}_{3}-0.33 \mathrm{PbTiO}_{3}$ single crystal/polymer composites with 2-2 connectivity," Smart Materials and Structures, vol. 18, no. 6, Article ID 065011, 11 pages, 2009.

[5] H. Cao, V. H. Schmidt, R. Zhang, W. Cao, and H. Luo, "Elastic, piezoelectric, and dielectric properties of $0.58 \mathrm{~Pb}\left(\mathrm{Mg}_{1 / 3} \mathrm{Nb}_{2 / 3}\right) \mathrm{O}_{3}-0.42 \mathrm{PbTiO}_{3}$ single crystal," Journal of Applied Physics, vol. 96, no. 1, pp. 549-554, 2004.

[6] R. Zhang, B. Jiang, W. Cao, and A. Amin, "Complete set of material constants of $0.93 \mathrm{~Pb}\left(\mathrm{Zn}_{1 / 3} \mathrm{Nb}_{2 / 3}\right) \mathrm{O}_{3}-0.07 \mathrm{PbTiO}_{3}$ domain engineered single crystal," Journal of Materials Science Letters, vol. 21, no. 23, pp. 1877-1879, 2002.

[7] R. Zhang, B. Jiang, and W. Cao, "Single-domain properties of $0.67 \mathrm{~Pb}\left(\mathrm{Mg}_{1 / 3} \mathrm{Nb}_{2 / 3}\right) \mathrm{O}_{3}-0.33 \mathrm{PbTiO}_{3}$ single crystals under electric field bias," Applied Physics Letters, vol. 82, no. 5, pp. 787-789, 2003.

[8] M. Guennou, H. Dammak, and M. P. Thi, "2T domainengineered piezoelectric single crystals: calculations and application to PZN-12\%PT poled along [101]," Journal of Applied Physics, vol. 104, no. 7, Article ID 074102, 6 pages, 2008.

[9] R. E. Newnham, D. P. Skinner, and L. E. Cross, "Connectivity and piezoelectric-pyroelectric composites," Materials Research Bulletin, vol. 13, no. 5, pp. 525-536, 1978.

[10] V. Yu. Topolov and C. R. Bowen, Electromechanical Properties in Composites Based on Ferroelectrics, Springer, London, UK, 2009. 
[11] L. V. Gibiansky and S. Torquato, "On the use of homogenization theory to design optimal piezocomposites for hydrophone applications," Journal of the Mechanics and Physics of Solids, vol. 45, no. 5, pp. 689-708, 1997.

[12] V. I. Aleshin, "Domain-orientation contribution into constants of the ferroelectric polydomain single crystal and piezoelectric ceramic," Zhurnal Tekhnicheskoi Fiziki, vol. 60, no. 1, pp. 179-183, 1990 (Russian).

[13] Y. Xu, Ferroelectric Materials and Their Applications, NorthHolland, Amsterdam, The Netherlands, 1991. 

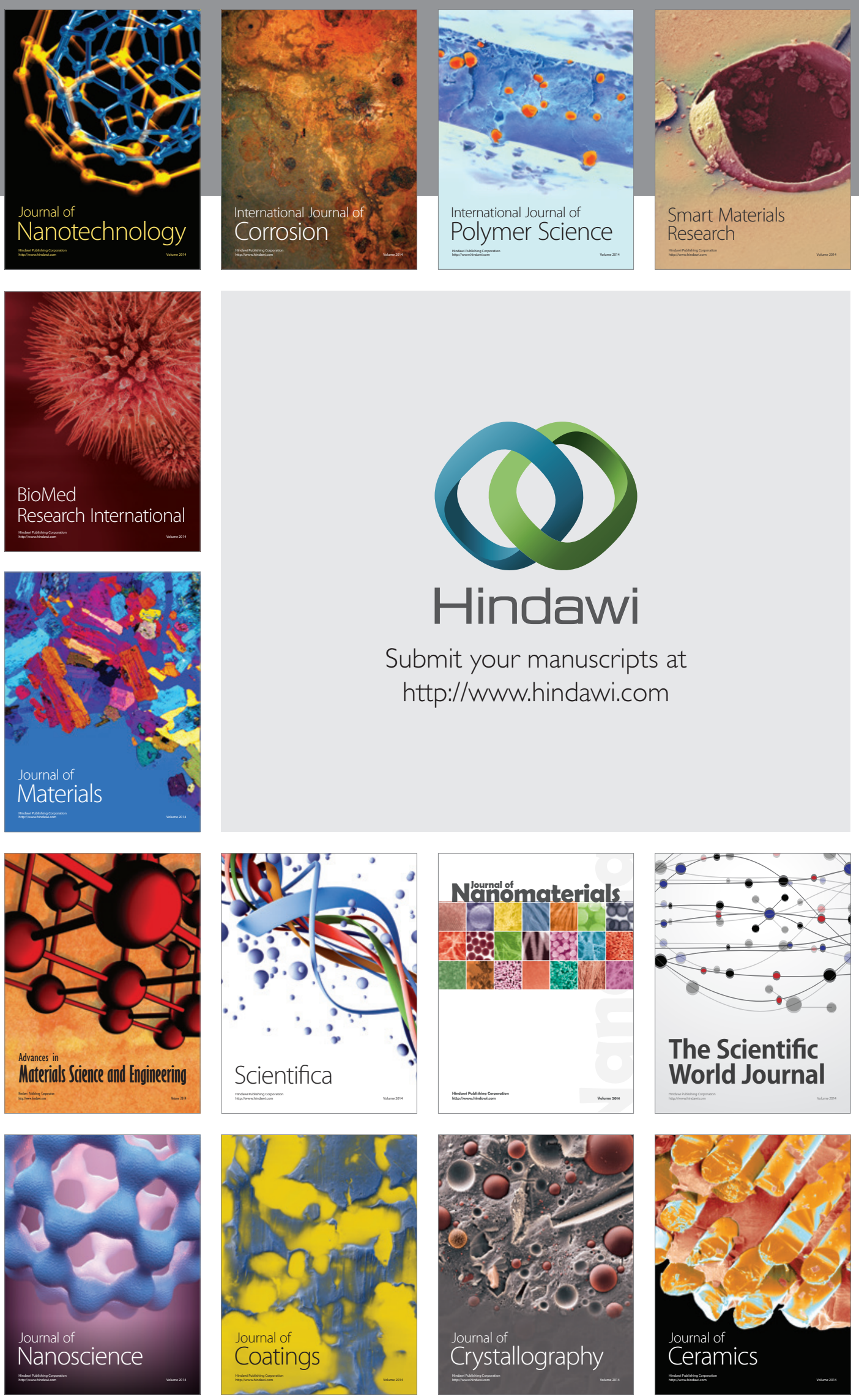

The Scientific World Journal

Submit your manuscripts at

http://www.hindawi.com

\section{World Journal}

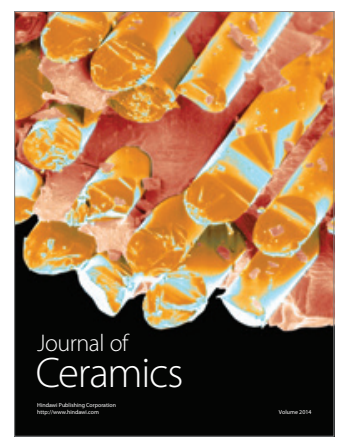

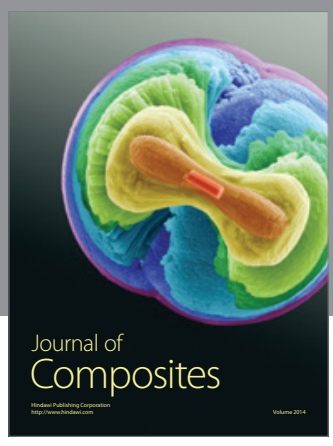
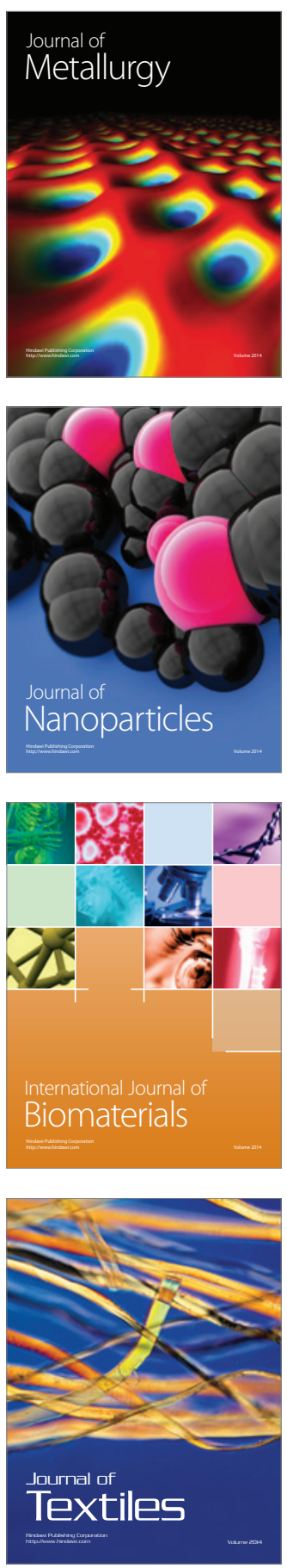